\title{
Electrifying chemistry with protonic cells
}

Scalable interconversion between chemical and electrical energy requires compact, selective and highly efficient reversible electrochemical cells. Now, protonic electrochemical cells with tailored catalysts and ceramic architecture are shown to operate reversibly with high performance and to be integrable with catalytic $\mathrm{CO}_{2}$ conversion.

José M. Serra

The rising availability and affordability of renewable energy is having a large impact in the industrial process and transport sectors. However, the intermittent nature of renewable electricity - mostly from solar and wind sources - means that energy systems are increasingly complex, and advanced technologies are required for energy storage, transportation and direct conversion of electricity into chemical products. Electrochemical energy storage, as realized in modern batteries and electrolyzers, is compact, modular and quiet and, therefore, is an attractive storage approach. Water electrolysis enables storage of energy in the hydrogen molecule, which can be converted back into electricity in a fuel cell or, alternatively, used in chemical processing. Among the different types of electrolyzers, the emerging technology based on protonic ceramic cells - those in which electron flow through the device is accompanied by a flow of protons through a ceramic electrolyte - is promising because of the potential for high energy efficiency and the ability to directly produce dry, pressurized hydrogen. Reversible $\mathrm{H}_{2}$ cells could provide increased energy capacity and flexibility for energy storage while enabling easy operation, as is the case for Li-ion batteries. However, electrode and electrolyte degradation and insufficient cell performance has hampered the development of reversible cells. Writing in Nature Energy, Chuancheng Duan, Ryan O'Hayre and co-workers at Colorado School of Mines now report a breakthrough in the development of protonic cells that makes it possible for them to operate with high efficiency in reversible modes, either producing hydrogen to store energy or oxidizing it with air to produce power ${ }^{1}$.

Research into ceramic proton conductors is quickly-evolving and the work by Duan, O'Hayre and colleagues is grounded in recent advances in mixed protonic-electronic steam and oxygen electrodes $^{2-3}$, fast protonic electrolytes ${ }^{4-6}$ and understanding of fundamental transport mechanisms $^{7}$. The researchers fabricate electrochemical cells that are based on electrolyte membranes composed of fast proton-conducting ceramics with a multi-cation-doped perovskite structure and highly-active electrodes for splitting water at intermediate temperatures of $450-600^{\circ} \mathrm{C}$ (Figure 1). The cells operate stably at very high Faradic efficiency $(>98 \%)$ and at outstanding current densities $\left(\sim 2 \mathrm{~A} / \mathrm{cm}^{2}\right)$ over $1200 \mathrm{~h}$. The reported high power 
density and the associated low cell resistance are achieved thanks to the finely-tuned steam electrode $\left(\mathrm{BaCo}_{0.4} \mathrm{Fe}_{0.4} \mathrm{Zr}_{0.1} \mathrm{Y}_{0.1} \mathrm{O}_{3-\delta}\right)$ in combination with the thin electrolyte $\left(\mathrm{BaCe}_{0.7} \mathrm{Zr}_{0.1} \mathrm{Y}_{0.1} \mathrm{Yb}_{0.1} \mathrm{O}_{3-\delta}\right)$ that exhibits notably low electronic conductivity, coupled with high protonic conductivity at relatively low temperatures. Apart from the excellent cell performance, stability over time and energy efficiency, the researchers provide clear understanding of ion transport pathways under galvanic cell operation that is built on the researchers' previous development of robust modelling methods ${ }^{8}$.

The selective transport of protons and the intermediate temperature operation range of protonic ceramic cells enable the use of external heat from other sources, such as industrial waste heat or solar/geothermal heat, which can lead to superior energy efficiency. As exemplified by Duan, O'Hayre and colleagues, this can reach over $100 \%$ if the waste heat is considered to be "free". In addition, this temperature range allows protonic electrochemical cells to be combined with other kinds of processes, as happens, for instance, in electrochemical catalytic membrane reactors that are attracting growing industrial interest.

Electrification of industrial processes based on renewable energy is a crucial pathway to reach carbon neutrality within the coming decades and electrochemical separators and reactors are suitable approaches to achieve this in a flexible and efficient manner ${ }^{9}$. In this context, the industrial production of carbon-based molecules - such as polymers, commodities and drugs, in addition to fuels - from $\mathrm{CO}_{2}$ and electricity is now the subject of intense research. This aspect is also addressed by Duan, O'Hayre and colleagues, as they illustrate the use of their protonic electrolyzer to produce hydrogen in combination with the catalytic conversion of $\mathrm{CO}_{2}$ into methane and other hydrocarbons $\left(\mathrm{C}_{2}-\mathrm{C}_{3}\right)$.

This kind of intimate integration of protonic membranes and catalytic reactors has a couple of advantages. First, thermal processes can be coupled (e.g. heat from ohmic losses and enthalpy of hydrocarbon synthesis and water splitting reactions) leading to higher overall energy efficiency, as previously shown elsewhere ${ }^{10}$. Second, very high product yields and selectivity can be achieved, thanks to the equilibrium shift ${ }^{11}$. In the case of $\mathrm{CO}_{2}$ conversion, as shown by Duan, O'Hayre and colleagues, high energy-efficiency can be achieved by properly balancing endothermic water splitting, exothermic $\mathrm{CO}_{2}$ hydrogenation reactions, electrical heat and external 'free heat'. In the specific case of reductive $\mathrm{CO}_{2}$ conversion, the process could be further intensified if water molecules, which are produced in the reaction, are selectively extracted from the $\mathrm{CO}_{2}$-reaction media. 
This latter effect could potentially be achieved in the future by providing additional oxygen-ion conductivity to the electrolyte of the protonic cell. This co-ionic character in protonic ceramics has been successfully explored for different applications elsewhere ${ }^{12}$ and requires adjusting the electrolyte composition and cell operation conditions. Co-ionic transport through the electrolyte would facilitate the in situ water conversion to regenerate hydrogen during $\mathrm{CO}_{2}$ hydrogenation and simultaneously shift the equilibrium to boost the formation of synthetic hydrocarbons (Figure 1d). However, reaching sufficient co-ionic character at temperatures below $500{ }^{\circ} \mathrm{C}$ is still a great challenge.

Despite the high electrochemical performance achieved by the researchers, further developments are necessary to consolidate this appealing electrolysis technology. Namely, the electrochemical cells should be scaled up into larger flat cells or stacks and, then, the stable and high-efficiency operation should be again validated. In addition, the operation under application-sound conditions is necessary, for instance, by testing at higher total steam pressure or higher pressure in the produced hydrogen. Although these steps may require redesigning of cell geometry and engineering of the stack assembly, they are typical in technology development and are already being addressed by projects on solid-oxide electrolysis cells (SOECs) ${ }^{13}$ and protonic membrane reformers for pressurized hydrogen generation ${ }^{11}$. In any case, the reported achievements by Duan, O'Hayre and colleagues, open the door for a multitude of applications in sustainable energy management and efficient electrification of industrial processes.

José M. Serra is at the Institute of Chemical Technology (ITQ), a joint center of the Consejo Superior de Investigaciones Científicas (CSIC) and the Universtitat Politècnica de València (UPV), 46022 Valencia, Spain

Correspondence to José M. Serra (jmserra@itq.upv.es) 


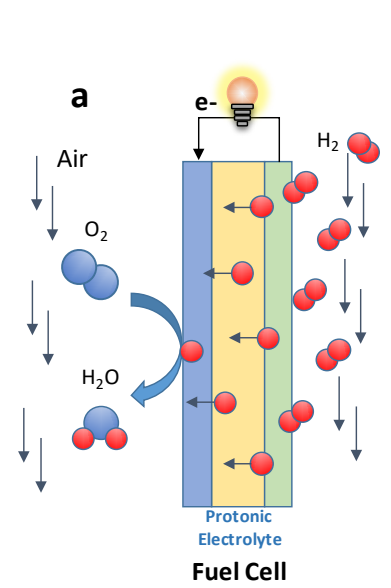

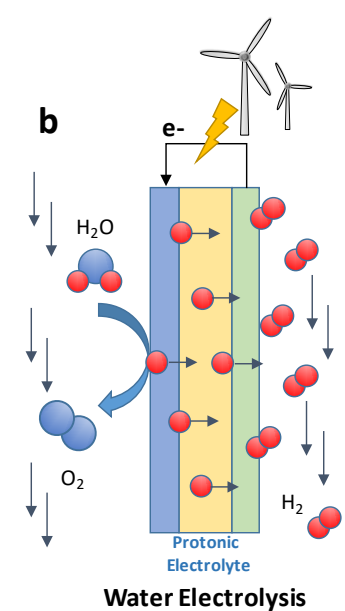

Water Electrolysis
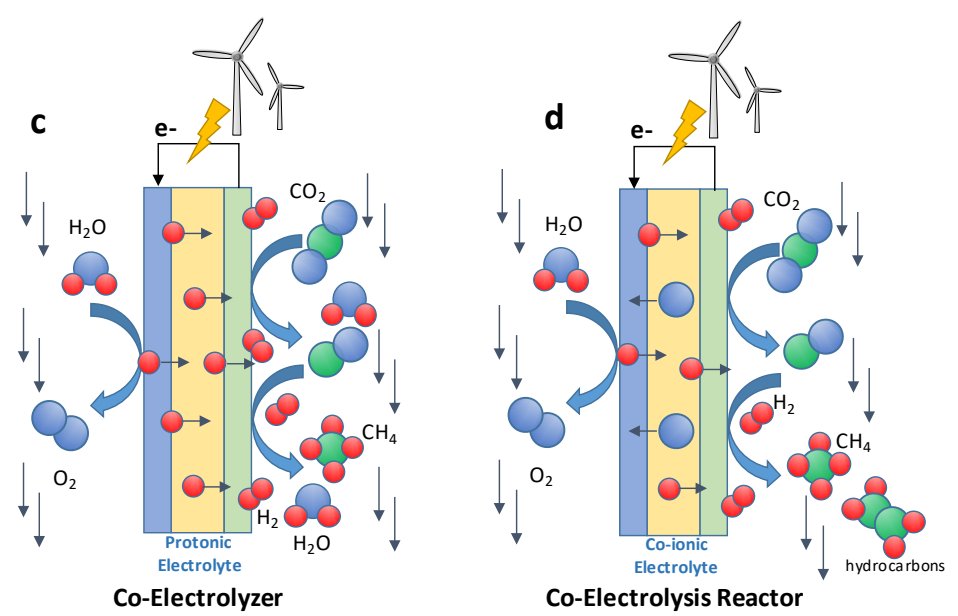

Figure 1 | Reversible protonic cells for flexible energy storage and synthetic chemistry. The protonic ceramic cell in (a) fuel cell mode, (b) water electrolysis mode, and (c) coelectrolysis mode to produce $\mathrm{CH}_{4}$. The positive air/steam electrode is shown in blue and is composed of $\mathrm{BaCo}_{0.4} \mathrm{Fe}_{0.4} \mathrm{Zr}_{0.1} \mathrm{Y}_{0.1} \mathrm{O}_{3-\delta}$ the protonic electrolyte is in yellow and composed of $\mathrm{BaCe}_{0.7} \mathrm{Zr}_{0.1} \mathrm{Y}_{0.1} \mathrm{Yb}_{0.1} \mathrm{O}_{3-\delta}$ and the negative $\mathrm{H}_{2}$ electrode, in green, is based on $\mathrm{Ni}$ and $\mathrm{BaCe}_{0.7} \mathrm{Zr}_{0.1} \mathrm{Y}_{0.1} \mathrm{Yb}_{0.1} \mathrm{O}_{3-\delta}$. (d) Future realization of the protonic ceramic cell with additional oxygen-ion conductivity in co-electrolysis mode for the direct synthesis of hydrocarbons.

\section{References:}

1 Duan et al. Highly efficient reversible protonic ceramic electrochemical cells for power generation and green fuels production, Nature Energy (2019).

2 Choi, S. et al. Exceptional power density and stability at intermediate temperatures in protonic ceramic fuel cells. Nature Energy 3, 202-210, doi:10.1038/s41560-017-0085-9 (2018). 3 Duan, C. et al. Readily processed protonic ceramic fuel cells with high performance at low temperatures. Science 349, 1321-1326, doi:10.1126/science.aab3987 (2015)

4 Fabbri, E., Pergolesi, D. \& Traversa, E. Materials challenges toward proton-conducting oxide fuel cells: a critical review. Chemical Society Reviews 39, 4355-4369, doi:10.1039/b902343g (2010).

5 Yang, L. et al. Enhanced Sulfur and Coking Tolerance of a Mixed lon Conductor for SOFCs: BaZr0.1Ce0.7Y0.2-xYbxO3-delta. Science 326, 126-129, doi:10.1126/science.1174811 (2009).

6 Leonard, K. et al. Efficient intermediate-temperature steam electrolysis with Y : SrZrO3$\mathrm{SrCeO} 3$ and $\mathrm{Y}$ : BaZrO3-BaCeO3 proton conducting perovskites. Journal of Materials Chemistry A 6, 19113-19124, doi:10.1039/c8ta04019b (2018). 
7 Zohourian, R., Merkle, R., Raimondi, G. \& Maier, J. Mixed-Conducting Perovskites as Cathode Materials for Protonic Ceramic Fuel Cells: Understanding the Trends in Proton Uptake. Advanced Functional Materials 28, doi:10.1002/adfm.201801241 (2018).

$8 \mathrm{Zhu}, \mathrm{H}$. and Kee, R. J. Modeling Protonic-Ceramic Fuel Cells with Porous Composite Electrodes in a Button-Cell Configuration. J. Electrochem. Soc. 164, F1400-F1411 (2017).

9 Schiffer, Z. J. \& Manthiram, K. Electrification and Decarbonization of the Chemical Industry. Joule 1, 10-14, doi:10.1016/j.joule.2017.07.008 (2017)

10 Ding, D. et al. A novel low-thermal-budget approach for the co-production of ethylene and hydrogen via the electrochemical non-oxidative deprotonation of ethane. Energy \& Environmental Science 11, 1710-1716, doi:10.1039/c8ee00645h (2018)

11 Malerod-Fjeld, H. et al. Thermo-electrochemical production of compressed hydrogen from methane with near-zero energy loss. Nature Energy 2, 923-931, doi:10.1038/s41560-0170029-4 (2017)

12 Morejudo, S. H. et al. Direct conversion of methane to aromatics in a catalytic co-ionic membrane reactor. Science 353, 563-566, doi:10.1126/science.aag0274 (2016)

13 Fang, Q., Blum, L. and Menzler, N. H. Performance and Degradation of Solid Oxide Electrolysis Cells in Stack. J. Electrochem. Soc. 162, F907-F912 (2015) 